\title{
Research on the Practice of Teachers' Dynamic Assessment Based on the Theory of the Zone of Proximal Development
}

\author{
Boya $\mathrm{Li}^{1, *, \dagger}$, Wenrui $\mathrm{Li}^{2, *, \dagger}{ }^{,}$Jiabao $\mathrm{Wu}^{3, *, \dagger}$ \\ ${ }^{1}$ Fujian Agriculture and Forestry University, Fuzhou, Fujian, China \\ ${ }^{2}$ Beijing Normal University - Hong Kong Baptist University United International College, Zhuhai, Guangdong, China \\ ${ }^{3}$ University Putra Malaysia, Serdang, Selangor, Malaysia \\ ${ }^{*}$ Corresponding author. Email: ${ }^{1}$ author11747746235@qq.com, ${ }^{2}$ erika654321@163.com \\ 3author3gs61779@student.upm.edu.my \\ Those authors contributed equally.
}

\begin{abstract}
The zone of proximal development was originally a concept in psychology, which was later introduced into the theory of second language acquisition. How to apply this theory to dynamic assessment of students in second language acquisition class is still a difficult problem for teachers. Our purpose is to study how teachers locate students' ZPD in second language acquisition classes and make dynamic assessment of students through asking questions or other forms of methods which level students are in. This assessment is dynamic, is not a test to give the student to the layered assessment to the degree of knowledge.
\end{abstract}

Keywords: The zone of proximal development, second language acquisition, teaching.

\section{INTRODUCTION}

Soviet psychologist Vygosky and his colleagues put forward sociocultural theory in the 1920s and 1930s, which was subsequently recognized by scholars in psychology, pedagogy and applied linguistics, among which the theory of the zone of Proximal development (ZPD) is more influential. Vygotsky (1978) defined the ZPD as "the distance between the actual developmental level as determined by independent problem solving and the level of potential development as determined through problem solving under adult guidance or in collaboration with more capable peers" (p. 86) [1]. Ohta developed Vygostky's definition of ZPD suitable for the context of classroom second language acquisition (SLA), and defined the ZPD as "the ZPD as the difference between the L2 learner's developmental level as determined by independent language use, and the higher level of potential development as determined by how language is used in collaboration with a more capable interlocutor. (Ohta, 1995) [2].

The dynamic assessment theory is also derived from the theory of "zone of proximal development", which is mostly used in children's cognitive ability tests and is widely regarded as an effective measure of "zone of proximal development". Different from the traditional assessment method, the process of the test involves the interaction between the evaluator and the participant, and the evaluator discovers the potential learning cognitive ability of learners by observing their performance in various complex activities.

In recent years, more and more language educators have begun to pay attention to the application of the zone of Proximal development in second language acquisition (SLA) classrooms. As this concept has been concreted, expanded and applied, linguists have developed a variety of teaching and assessment methods, which are now widely used in teaching. Many teachers focused on the application of dynamic assessment theory in teaching in order to better locate students' ZPD and promote students' language learning. However, there are some problems in applying theory to the classroom. A challenging problem which arises in this domain is that teachers do not know how to accurately locate students' ZPD through dynamic assessment in second language acquisition classrooms. This paper will explore teachers' teaching practice of determining students' ZPD through dynamic assessment 
in SLA classrooms, so that ZPD theory can be better developed in the SLA classrooms and guide teachers to achieve better results in teaching.

\section{TEACHERS' DYNAMIC FORMATIVE ASSESSMENT OF STUDENTS}

Interpretations of Vygotsky's of the zone of proximal development have produced two different views on dynamic assessment. The first view is that the learner's zone of proximal development can be measured as an individual trait, which can be measured in a different teaching. To maintain a certain degree of stability in the environment, this view advocates integrating teaching into assessment. The second point of view advocates integrating dynamic formative assessment into classroom teaching, and that assessment occurs in the learner's most proximal development zone.

Two different views apply to second language dynamic assessment. First, the learner's zone of proximal development can be measured the number of words. This method can integrate teaching into assessment process. The second teacher hold up a dynamic formative assessment into classroom teaching, and that assessment could occur in the learner's most proximal development zone.

\section{1 concept of students' dynamic assessment in classroom teaching of English second language acquisition}

The second dynamic assessment view derived from zone of proximal development theory advocates integrating assessment into teaching practice, focusing on teachers' teaching in the daily classroom environment. In the most fundamental sense, assessment should be regarded as an integral part of teaching, not the end of teaching. Therefore, research on dynamic assessment should focus more directly on the assessment methods integrated into teaching. In this type of research, the interaction model based on teacherstudent interaction, peer interaction, or computer environment has become the main assessment method.

The main goal of assessment integrated into teaching is to optimize teaching, and assessment procedures and tools serve this goal. Assessments that take place in the recent development zone are no longer the learner's progress but the learner's response to different forms of "scaffolding", in other words, the interdependence of the learning and teaching processes. In the interactive mode of dynamic assessment, the adjustment of learning results mainly comes from the design of the teaching environment, and the teaching design reflects the learning concepts adopted by the teacher in the established teaching environment. Every aspect of teaching, such as materials provided to learners, task objectives and instructions, types of social interaction, etc., may become a means of regulating the teaching process and the learning process. The assessment materials mainly come from observations of student behavior, dialogues between individuals or groups, samples of student activities, etc. Interactive dynamic assessment is an interaction process guided by teaching and learning goals, rather than a mere measurement process.

The interaction of the teaching environment has created a diversified recent development zone. In such an environment, teacher observation and teacher-student dialogue have become the main forms of assessment. The exploration of a child's most recent development area at a certain time can be investigated through the child's ongoing social interaction with others. The goal of assessment is to regulate the children's learning in the recent development zone, not to obtain measurement information about the characteristics of the recent development zone.

\subsection{Dynamic assessment system of English second language acquisition classroom based on nearest Development Zone Theory}

From the development of the two dynamic assessment concepts, we can draw conclusions that are unanimously recognized and accepted by the community of researchers, which are concentrated in the following aspects:

Intermediary strategies with logical meaning are more conducive to the improvement of students' test scores. Some researchers have systematically compared the relative effectiveness of several different pre-test methods, and arranged logical mediation, progressive promotion [3], and other types of intervention activities between the pre-test and post-test. The results show that the logic is the intermediary strategy can promote the improvement of students' test scores better than other types of intervention activities.

The intermediary strategy used in the assessment can be transferred to the solution of new problems. A series of studies on the concept of intermediary and operational strategies in the dynamic assessment show that the nearer transfer is easier to obtain, and only when the intermediary teaching contains some teaching strategies designed to promote the transfer, the more distant transfer is possible [4]. In other words, migration does not happen by accident, nor can it be acquired by accident. It must be promoted by purposeful guidance and activities.

Dynamic assessment can enable teachers to obtain more effective information. Many studies have shown that teachers can obtain reliable information and practical help from dynamic assessments [5]. The conclusions drawn by static tests are often unable to help teachers choose teaching content and teaching 
strategies. As a research tool, dynamic assessment can capture knowledge and information that is difficult to obtain in static tests, especially when the subject's speech activity is impaired or has morbid psychology. When the ability is hindered, the superiority of dynamic evaluation is more obvious.

\subsection{Teachers' dynamic assessment and implementation in the classroom teaching practice of English second language acquisition}

From the development of the two dynamic assessment concepts, we can draw conclusions that are unanimously recognized and accepted by the community of researchers, which are concentrated in the following aspects:

First, after teaching and intermediary, students' test scores can be improved. This conclusion is shared by almost every researcher of dynamic assessment. The improvement of students' test scores depends on the type and the purpose of teaching, the specific characteristics of individual's cognitive impairment, and the psychological distance between the teaching content and the test content.

Second, Intermediary strategies with logical meaning are more conducive. Some researchers have systematically compared the relative effectiveness of several different pre-test methods and arranged logical mediation, progressive promotion, and other types of intervention activities between the pre-test and post-test. The results show that the logic is the intermediary strategy can promote the improvement of students' test scores better than other types of intervention activities.

Third, the intermediary strategy used in the assessment can be transferred to the solution of new problems. A series of studies on the concept of intermediary and operational strategies in the dynamic assessment shows that the nearer transfer is easier to obtain, and only when the intermediary teaching contains some teaching strategies designed to promote the transfer, the more distant transfer is possible. In other words, language migration does not happen by accident, nor can it be acquired by accident. It must be promoted by purposeful guidance and activities.

\section{APPLICATION OF DYNAMIC EVALUATION IN CLASSROOM TEACHING PRACTICE OF ENGLISH SECOND LANGUAGE ACQUISITION}

\subsection{Analysis on the current situation of classroom teaching of English second language acquisition}

Generally speaking, there are many problems in second language acquisition teaching, but both teachers and students say that language teaching will have a bright future. They also agree that second language acquisition is a very important life skill. From the papers written by others, we have summarized three problems, which are briefly described from three aspects: teachers, students and education system.

For teachers, as Chen (2016) [6] suggested, the problems mainly include the following aspects. The first is that teachers do not know how to effectively teach students some specific contents, such as grammar, such as writing. Second, it is difficult for teachers to correct students' mistakes in some specific content teaching, such as grammar. Third, teachers' cognitive errors in some concepts. For example, according to An (2000) [9], they think that universities do not need to teach grammar, and oppose grammar and communicative teaching. In writing class, according to Liu (2015) [8], we can see other problems. Second language classes often adopt static teaching methods such as appreciating model essays and introducing writing skills. Moreover, the writing evaluation methods all pass the final quality score of the composition, and the evaluation contents and standards are mostly based on the language, ignoring the content of students' thinking level in writing.

In addition to the differences between students and teachers on explicit and implicit grammar teaching, as Chen (2016) [6] mentioned, students' unilateral problems are as follows. The first is that students do not know how to learn effectively in teaching. Second, students do not know how to apply what they have learned to real life.

As for the education system, an (2000) [9] pointed out the following problems, saying that the accuracy and adaptability of teaching hours and teaching materials cannot be guaranteed, this phenomenon is very common in college grammar education. She also mentioned the lack of supervision mechanism in grammar teaching. All these are limiting college grammar teaching, even the whole second language acquisition teaching.

\section{2 classroom teaching practice of English second language acquisition and construction of student dynamic evaluation system}

Different papers give different answers to what the dynamic evaluation system should look like. Wang (2019) [7] summarized six adjustment strategies: Learners' self-verification, reminding direction, determining the field of specific problems, metalanguage clues, providing answers and providing explanations.

Different from the former, Shen and Xiao (2021) [10] proposed two general directions of intervention and interaction to dynamically evaluate students. Among 
them, the intervention that emphasizes the speed and efficiency of learning can be divided into "sandwich mode" and "cake mode". "Sandwich mode" means that learners need to receive two tests before and after the intervention, and measure the change of students' ability by comparing the differences between the tests. The cake mode means that students immediately accept the intervention and guidance of the evaluator when they encounter difficulties. The evaluator observes and records the amount and difficulty of prompts required by learners, and then evaluates learners' cognitive ability through learning rate and transfer degree, so as to predict learners' future learning potential. The interactive dynamic assessment she mentioned emphasizes the assessment of students' psychological development potential. The evaluator adjusts the learning task through communication with students, so as to stimulate students' potential, that is, to explore students' ZPD. Under such a dynamic assessment, the evaluator will not ask the students what they know now, but focus on how the students deal with the new task. Such a dynamic assessment no longer refers only to a set of fixed standards, nor to the performance of individuals in the population. The basis for judging students' progress is their development in this process.

However, the above articles also have their own biases. For example, we only see the parts that need to be improved in English teaching and put forward the improvement methods. Few people pay attention to the parts that need to be retained, or the excellent parts in previous English teaching. Few people pay attention to why these parts do not need to be changed, and analyze the effect of these parts on students. Moreover, almost all articles have their own targeted parts. For example, for the grammar part of college foreign language education, or for college foreign language teaching. Their examples are often special, but the problems analyzed are often macro. These articles generally have the problem of unequal angles of examples and conclusions. Furthermore, the objects they analyze are often the subjects involved in teaching. As listed above, these three subjects are, students, education system and teachers. In the future studies, we can try to find new subjects other than the three.

\subsection{Implementation of ZPD theory teaching strategy in classroom teaching practice of English second language acquisition and students' dynamic assessment.}

Dynamic assessment (DA) pointed to an evaluation of "thinking, perception, learning and problem solving" through a teaching procedure aimed at changing cognitive functioning. This provides a reference for teachers to implement dynamic assessment in second language acquisition (SLA) classrooms.
In the second language acquisition class, we can use the method of questioning to locate their ZPD. In the second language acquisition class, teachers can first invite students to ask questions about the class content, or ask students how they think about the text. When students give a answer after considering, teacher can infer what he has mastered from the questions asked by students. By inviting students ask questions, the teacher takes time to observe where the student is located in his phase space of learning. And the teacher is able to enter into their perspective. What's more, the teacher can determine the students' potential for this type of knowledge and decide whether to teach other knowledge related to what they have mastered. In this process, the teacher narrowed her judgment on the student's ZPD. It should be noted that the judgment of students' mastery level is not static, but should be constantly adjusted according to the questions students ask, so as to achieve the goal of common progress. This dynamic assessment runs through the learning process of students, and changes the static evaluation to focus only on students' past achievements and development tendency, and treats students as developing people.

The concept closely related to the zone of proximal development is scaffolding. After determining the students' ZPD, Teachers can use scaffolding instruction, that is, a process through which a teacher adds supports for students in order to enhance learning and aid in the mastery of tasks. The teacher does this by systematically building on students' experiences and knowledge as they are learning new skills, these supports are temporary and adjustable. Under this guidance, students can quickly move from one area of the Zone of Proximal Development to the next, accelerating the accumulation of knowledge. And also, cooperative learning can be used to build scaffolding. At this point, students work with a partner or a small cooperative group to complete tasks in the class. In the class, students were free to ask questions, provide feedback and support their peers in learning new material. This teaching style provides an incentive for students to take a more active role in their own learning.

\section{CONCLUSION}

From the above analysis, it can be seen that the use of dynamic assessment to locate students' ZPD is still in a stage of continuous exploration, and there are certain deficiencies, which need to be improved and deepened.

We also found that teachers can obtain dynamic assessment of students through interaction in SLA classes, so as to better understand the potential of students and achieve better results in subsequent teaching. 


\section{REFERENCES}

[1] L. S. Vygotsky, Mind in Society: The development of higher psychological processes, Harvard University Press, 1978.

[2] A. S. Ohta, Applying sociocultural theory to an analysis of learner discourse: Learner-learner collaborative interaction in the zone of proximal development, in: H. Bahiyyih (Eds.), Issues in Applied Linguistics, Los Angeles, California, 1995, vol.6, no.2, pp.96. DOI:10.1109/IWQoS.2010.5542719

[3] S. M. Brookhart, Developing measurement theory for classroom assessment purposes and uses, in: J. Benson (Eds.), Educational measurement Issues and practice, Wiley Periodicals, Medford, Massachusetts, 2003, pp.5-12. DOI: https://doi.org/10.1111/j.17453992.2003.tb00139.x

[4] F. Lauchlan, J. T .Elliott , The psychological assessment of learning potential, in: A. Jones (Eds.), British Journal of Educational Psychology, Sheridan press,N.Y.,Hudson, 2001, vol. 71, no. 4, pp.

$647-$

665.DOI:https://doi.org/10.1348/00070990115871 2

[5] E.Peña, A.Lglesias , C.S.Lidz, Reducing Test Bias Through Dynamic Assessment Of Children's Word Learning Ability, in: F, Martha (Eds.)American Journal of Speech-Language Pathology, Rockcille Pike, Mqryland, Rockville, Vol. 10, No.2, 2001, pp. 138-154. DOI: https://doi.org/10.1044/10580360(2001/014)

[6] F. Chen, An investigation into the current situation of English grammar teaching in a vocational school (Doctoral dissertation), Jiangxi Normal University, 2016.

[7] J. Wang, Explore the Mechanism of interactionist dynamic assessment for Chinese EFL learners reading comprehension performance (Doctoral dissertation), Guangdong University of Foreign Studies, 2019.

[8] L. Liu, On the theory of dynamic assessment in second language learning, in: T. Zhang (Ed.), Journal of Xi'an Aeronautical University, vol.36, Shaanxi, Xi'an, 2018, pp. 73-76. DOI: https://doi.org/10.3969/j.issn.10089233.2018.02.015

[9] M. An, Problems in college English grammar teaching, in: Z. Zhuang (Ed.), Foreign Language World, 000(003), Shanghai, 2000, pp. 38-40+50.
DOI: https://doi.org/CNKI:SUN:WYJY.0.2000-03009.

[10] Y. Shen, W. Xiao, Dynamic Assessment - A New Perspective of Second Language Assessment, in: J. Wang (Ed.), Journal of Huangshan University, 23(2), Anhui, Huangshan, 2021, pp.117-120. DOI: https://doi.org/10.3969/j.issn.1672-

447X.2021.02.024 